\title{
Comparison Between Standard Vs. High Dosing Venous Thromboembolism (VTE) Prophylaxis in COVID19 Critically III Patients: A Multicenter, Observational Study
}

\section{Ohoud Aljuhani (D OALJUHANI@KAU.EDU.SA)}

King Abdulaziz University Faculty of Pharmacy https://orcid.org/0000-0002-8078-564X

Khalid Alsulaiman

King Abdulaziz Medical City

Awattif Hafiz

King Abdulaziz University Faculty of Pharmacy

Khalid Eljaaly

King Abdulaziz University Faculty of Pharmacy

\section{Aisha Alharbi}

King Abdulaziz University Hospital

\section{Rahma Algarni}

King Abdulaziz University Hospital

\section{Sarah Al Homaid}

King Saud bin Abdulaziz University for Health Sciences College of Pharmacy

\section{Khawla Al Qahtani}

King Saud bin Abdulaziz University for Health Sciences College of Pharmacy

\section{Tareq Alsulaiman}

Imam Abdulrahman Al Faisal Hospital

\section{Ramesh Vishwakarma}

KAIMRC: King Abdullah International Medical Research Center

\section{Ghassan Al Ghamdi}

King Saud bin Abdulaziz University for Health Sciences College of Medicine

\section{Mai Alalawi}

Children's Cancer Hospital Egypt 57357

\section{Research}

Keywords: COVID-19, SARS-Cov-2, VTE prophylaxis, DVT prophylaxis, Enoxaparin, Heparin, Critically ill, Intensive Care Units (ICUs). 
Posted Date: May 6th, 2021

DOl: https://doi.org/10.21203/rs.3.rs-486818/v1

License: (c) (i) This work is licensed under a Creative Commons Attribution 4.0 International License. Read Full License 


\section{Abstract}

Background: There is uncertainty about the appropriate dosing regimen, safety, bleeding risk, and the predisposing factors for thrombosis/bleeding risk in critically ill COVID-19 patients. Also, the available evidence is limited and depends either on observational studies or randomized trials with small sample size. Thus, the aim of the study is to determine the optimal dosing of pharmacological VTE prophylaxis in critically ill patients with COVID-19 patients.

Methods: A multicenter, retrospective, cohort study conducted at two governmental tertiary hospitals in Saudi Arabia. All critically ill COVID 19 patients who received pharmacological VTE prophylaxis and were admitted to Intensive Care Units (ICUs) between March 1st, 2020 to January 31st, 2021 were included. Patients who received Standard dosing VTE prophylaxis were compared to patients who received high dosing pharmacological VTE prophylaxis.

Results: A total of 758 patients were screened; 565 patients were included in the study. We matched 352 patients using propensity score matching (1:1) according to the baseline severity scores (i.e., APACHE II score, SOFA score), history of CKD, and AKI within 24 hours of ICU admission. The differences in venous thromboembolism (OR $(95 \% \mathrm{Cl}): 0.75(0.16-3.38)$, p-value $=0.70)$ and any case of thrombosis $(\mathrm{OR}$ $(95 \% \mathrm{Cl}): 1.22(0.52-2.86), \mathrm{p}$-value $=0.64)$ were not statistically significant between the two groups. In contrast, minor bleeding was associated with the use of high dosing regimen of VTE prophylaxis (OR $(95 \% \mathrm{Cl}): 3.39(1.08-10.61), \mathrm{p}$-value $=0.04)$. There was no difference in the 30 -day ICU mortality nor inhospital mortality between the two groups (OR $(95 \% \mathrm{Cl}): 1.26(0.77-2.05)$, $\mathrm{p}$-value $=0.36$ and $\mathrm{OR}(95 \% \mathrm{Cl})$ : $1.05(0.66-1.68), \mathrm{p}$-value $=0.83$ respectively) .

Conclusion: High dosing pharmacological VTE prophylaxis in critically ill COVID-19 patients was not associated with VTE, thrombosis, or mortality benefits but led to an increased risk of minor bleeding. Further randomized clinical and interventional studies are required to confirm our findings.

\section{Background}

Coronavirus disease 2019 (COVID-19) is an infectious disease that caused pandemic and serious global issues, caused by an RNA virus named severe acute respiratory syndrome coronavirus 2 (SARS-CoV-2). The clinical presentation of infected patients is heterogeneous, ranging from asymptomatic to severe pneumonia accompanied with complications like respiratory failure, leading to mechanical ventilation and ICU admission, or death (1). Several risk factors were reported to be associated with increased mortality of COVID-19 hospitalized patients. Including elevated D-dimer level (>1 mcg/ml), older ages, cardiovascular diseases, diabetes mellitus, obesity, and high baseline sequential organ failure assessment (SOFA) score (2,3). One of the crucial aspects of the severe phase of COVID-19 is host inflammatory response. The excess release of the host's cytokines leads to capillary damage, thrombosis, and organ dysfunction (3). 
Although COVID-19 targets mainly the respiratory system, several organs can be predisposed, including the vascular system. The pathogenesis of vascular damage involves several mechanisms; excessive proinflammatory cytokines causing systemic inflammation and endothelial dysfunction were among the most important mechanisms. In turn, abnormal function of prothrombic endothelial and platelet activation leads to prothrombic events (2). A recently published meta-analysis that involved 42 studies reported the rates of venous thromboembolism (VTE), deep venous thrombosis (DVT), pulmonary embolism (PE) in COVID-19 patients were $21 \%, 20 \%, 13 \%$, respectively. Those rates in critically ill COVID19 patients were remarkably higher $(31 \%, 28 \%, 19 \%)$, respectively. Besides, the risk of mortality with COVID-19 was significantly higher in patients who experienced thromboembolic events (4). In a recent multicenter cohort study, the rate of thrombosis was $11.4 \%$ in COVID-19 ICU patients regardless of anticoagulants prophylaxis use (5). Consequently, the International Society of Thrombosis and Hemostasis (ISTH) and The American Society of Hematology (ASH) recommend the use of prophylactic anticoagulants in all COVID-19 hospitalized patients (whether critically ill or not) unless there is a contraindication or evidence of increases the risk of bleeding (4).

Dosing of anticoagulation prophylaxis in critically ill COVID-19 patients remains a considerable controversy. Current regimes rely more on physicians' decisions and expert opinions besides the fact that some experts push for higher anticoagulant doses due to the severity of the disease in ICU patients(4). A retrospective observation trial found a decrease in the mortality rate with anticoagulant treatment doses, although they were more presumably to require mechanical ventilation (6). In addition, several trials are ongoing that aim to provide robust evidence regarding the role and dosing of anticoagulants in COVID-19 patients $(7,8,9)$.

There is uncertainty about the appropriate dosing regimen, safety, bleeding risk, and the predisposing factors for thrombosis/bleeding risk in critically ill COVID-19 patients. Also, the available evidence is limited and depends either on observational studies or randomized trials with small sample size. Thus, the aim of the study is to determine the optimal dosing of pharmacological VTE prophylaxis in critically ill patients with COVID-19 patients.

\section{Methods}

\section{Study design and setting}

A multicenter, retrospective cohort study was conducted for critically ill patients aged $\geq 18$-years with confirmed COVID-19 who were admitted to the ICUs at two tertiary hospitals in Saudi Arabia from March 01, 2020, until January 31, 2021. Patients were excluded if not on pharmacological VTE prophylaxis, on low dose VTE prophylaxis (i,e, Enoxaparin $<40 \mathrm{mg} /$ day or UFH $15000 \mathrm{U} /$ day), on treatment dose of anticoagulation for other indication (s) (e.g., Atrial fibrillation.), active bleeding within 24 hours of ICU admission and/or have platelets count $<50,00010^{9} / \mathrm{L}$. 
Eligible patients were classified into two groups based on the VTE prophylaxis dosing intensity (Standard vs. high dosing) during ICU stay. Patients were followed during ICU stay. The two included hospitals were King Abdulaziz University Hospital, Jeddah (the primary site), and King Abdulaziz Medical City, Riyadh.

The Biomedical ethical research committee approved the study at King Abdulaziz University Hospital with Reference No $554-20$.

\section{Data collection}

We collected demographic data (See additional file 1), comorbidities, vital signs and laboratory tests, Acute Physiology and Chronic Health Evaluation II (APACHE II), Sequential Organ Failure Assessment (SOFA) and Nutrition Risk in Critically ill (NUTRIC) scores, Padua score, Glasgow Coma Score (GCS), acute kidney injury, fluid balance, mechanical ventilation (MV) needs and MV parameters (e.g., $\mathrm{PaO} 2 / \mathrm{FiO} 2$ ratio, Fio2 requirement) and inflammatory markers (CRP, procalcitonin) within 24 hours of ICU admission. Also, renal profile, liver function tests (LFTs), coagulation profile (i.e., INR, aPTT, fibrinogen) within 24 hours of ICU admission were collected. During ICU stay, radiological findings (using Ultrasound or CT scan as appropriate), major/minor bleeding data, and RBCs transfusion were recorded for the eligible patients. All patients were followed until they were discharged from the hospital or died during the in-hospital stay, whichever occurred first.

\section{Outcomes}

The primary endpoint was the incidence of thrombosis. The secondary endpoints were the related complication (s) during ICU stay (i.e., major bleeding, minor bleeding, RBC transfusion during ICU stay, respiratory failure requires MV), hospital LOS, ICU LOS, MV duration, 30-day ICU, in-hospital mortality, and ICU-readmission within 3 months.

\section{Definition (s)}

- Standard dosing VTE prophylaxis is defined as using either Enoxaparin $40 \mathrm{mg} /$ day or Unfractionated heparin (UFH) $15000 \mathrm{U} /$ day.

- High dosing VTE prophylaxis is defined as using VTE prophylaxis doses above the standard dosing but not as treatment dose.

- Treatment dose defined as using either Enoxaparin $1 \mathrm{mg} / \mathrm{kg} \mathrm{q} 12 \mathrm{hr}$ (or $1.5 \mathrm{mg} / \mathrm{kg}$ q24hr) or Unfractionated heparin (UFH) infusion.

- Major bleeding was defined as clinically overt bleeding associated with a fall $\geq \mathrm{Hb} 20 \mathrm{~g} / \mathrm{L}$, transfusion of $\geq 2 \mathrm{U}$ PRBC or whole blood, retroperitoneal or intracranial bleeding, or requiring urgent medical intervention. While minor bleeding was defined as those not fulfilling the criteria of major or clinically significant bleeding.

- Acute kidney injury (AKI) was defined using Acute Kidney Injury Network (AKIN) definition.

- Respiratory failure was defined as either hypoxemic respiratory failure $\left(\mathrm{PaO}_{2}<60 \mathrm{~mm} \mathrm{Hg}\right.$ with a normal or low arterial carbon dioxide tension $\left(\mathrm{PaCO}_{2}\right)$ or hypercapnic respiratory failure $\left(\mathrm{PaCO}_{2}>50\right.$ $\mathrm{mm} \mathrm{Hg}$ ) that requires invasive mechanical ventilation. 
- Thrombosis/infraction was defined using the International Classification of Diseases, Tenth Revision, Clinical Modification (ICD10-CM) code (i.e., myocardial infarction (MI), ischemic stroke, pulmonary embolism, deep vein thrombosis) during ICU stay.

\section{Data management and Statistical analysis}

We presented numerical variables (continuous variables) as mean and standard deviation (SD), or median and interquartile range (IQR), and categorical variables as number (percentage) as appropriate. The normality assumptions were assessed for all numerical variables using a statistical test (i.e., Shapiro-Wilk test) and graphical representation (i.e., histograms and Q-Q plots).

We compared categorical variables using the chi-square or Fisher exact test. We compared the normally distributed continuous variables using unpaired student t-test and other non-normally distributed continuous variables with the Mann-Whitney $U$ test. Baseline characteristics, baseline severity, and outcome variables were compared between the two groups. Multivariate logistic regression and generalized linear were used to find out the relationship between different regimens of VTE prophylaxis with different outcomes considered in this study after adjusting for the severity score (APACHE II and SOFA score), history of chronic kidney disease (CKD), and acute kidney injury (AKI) within 24 hours of ICU admission. The odds ratios (OR) and estimates with the $95 \%$ confidence intervals $(\mathrm{Cl})$ were reported for the associations.

We assessed model fit using the Hosmer-Lemeshow goodness-of-fit test. No imputation was made for missing data as the cohort of patients in our study was not derived from random selection. We considered a P-value of $\leq 0.05$ statistically significant, and we used SAS version 9.4 for all statistical analyses.

\section{Results}

Among 758 patients screened, 565 patients were included in the study who received pharmacological VTE prophylaxis at ICU admission. Patient characteristics and demographic data are described in supplemental data (Additional file 1). The high dosing regimen of pharmacological VTE prophylaxis was given to 185 patients, whereas 380 patients received a standard dosing regimen. We matched 352 patients using propensity score matching (1:1) according to the baseline severity scores (i.e., APACHE II score, SOFA score), history of CKD, and AKI within 24 hours of ICU admission. We observed that all included patients received early pharmacological VTE prophylaxis within 24 hours of ICU admission with $96.4 \%$ and $95.8 \%$ in standard and high dosing regimens, respectively.

\section{Demographic and Clinical Characteristics}

Most of the patients in both groups were men (72.3\%), and the average age of the patients was $60.9 \pm 14$ years (Additional file 1). Severity scores (i.e., APACHE II and SOFA scores), procalcitonin levels, fibrinogen levels, serum creatinine, acute kidney injury within 24 hours of ICU admission were higher in patients who received standard dosing of pharmacological VTE prophylaxis (Additional file 1). The most common 
comorbidities in both arms were diabetes mellitus (60\%), hypertension (55.9\%), and dyslipidemia (22.8\%). Moreover, chronic kidney disease and history of VTE were higher in standard dosing compared with high dosing of pharmacological VTE prophylaxis (Additional file 2). There were no significant differences in baseline and demographic characteristics after adjustment using propensity score matching for patients' baseline severity scores and acute kidney injury within 24 hours of ICU admission.

\section{Thrombosis/bleeding during ICU stay}

During ICU stay, for patients who received high dosing pharmacological VTE prophylaxis, venous thromboembolism (OR $(95 \% \mathrm{Cl}): 0.75(0.16-3.38)$, p-value $=0.70)$ and any case of thrombosis $(\mathrm{OR}$ $(95 \% \mathrm{Cl}): 1.22(0.52-2.86)$, p-value $=0.64)$ were not significant compared with standard dosing $($ Table 1$)$.

Table 1

Regression analysis for ICU complication (s) during ICU stay

\begin{tabular}{|c|c|c|c|c|c|}
\hline \multirow[t]{2}{*}{ Outcomes } & \multicolumn{2}{|c|}{ VTE prophylaxis } & \multirow{2}{*}{$\begin{array}{l}\text { P- } \\
\text { value } \\
\wedge \Lambda\end{array}$} & \multirow{2}{*}{$\begin{array}{l}\text { Odds Ratio (OR) } \\
(95 \% \mathrm{Cl})\end{array}$} & \multirow{2}{*}{$\begin{array}{l}\text { P- } \\
\text { value } \\
\$\end{array}$} \\
\hline & $\begin{array}{l}\text { High } \\
\text { dose }\end{array}$ & $\begin{array}{l}\text { Standard } \\
\text { dose }\end{array}$ & & & \\
\hline $\begin{array}{l}\text { Respiratory Failure Required MV, } \\
\mathrm{n} / \mathrm{N}(\%) \$^{*}\end{array}$ & $\begin{array}{l}23 / 66 \\
(34.8)\end{array}$ & $\begin{array}{l}26 / 73 \\
(35.6)\end{array}$ & 0.92 & $0.98(0.49,1.96)$ & 0.95 \\
\hline Any Thrombosis During ICU, $n / N(\%)$ & $\begin{array}{l}13 / 172 \\
(7.5)\end{array}$ & $\begin{array}{l}11 / 175 \\
(6.2)\end{array}$ & 0.64 & $1.22(0.52,2.86)$ & 0.64 \\
\hline $\begin{array}{l}\text { Venous Thromboembolism (VTE), } \\
\mathrm{n} / \mathrm{N}(\%)\end{array}$ & $\begin{array}{l}3 / 176 \\
(1.7)\end{array}$ & $\begin{array}{l}4 / 176 \\
(2.27)\end{array}$ & 0.70 & $0.75(0.16,3.38)$ & 0.70 \\
\hline Major bleeding, $\mathrm{n} / \mathrm{N}(\%)$ & $\begin{array}{l}9 / 174 \\
(5.2)\end{array}$ & $\begin{array}{l}7 / 171 \\
(4.09)\end{array}$ & 0.63 & $1.28(0.46,3.53)$ & 0.63 \\
\hline Minor bleeding, $\mathrm{n} / \mathrm{N}(\%)$ & $\begin{array}{l}13 / 173 \\
(7.5)\end{array}$ & $\begin{array}{l}4 / 171 \\
(2.3)\end{array}$ & 0.03 & $\begin{array}{l}3.39(1.08 \\
, 10.61)\end{array}$ & 0.04 \\
\hline $\begin{array}{l}\text { Requiring RBCs transfusion during } \\
\text { ICU stay, } \mathrm{n} / \mathrm{N}(\%)\end{array}$ & $\begin{array}{l}23 / 165 \\
(13.9)\end{array}$ & $\begin{array}{l}29 / 173 \\
(16.7)\end{array}$ & 0.47 & $0.80(0.44,1.46)$ & 0.46 \\
\hline $\begin{array}{l}\text { ICU readmission within } 3 \text { months, } \\
\mathrm{n} / \mathrm{N}(\%) ¥\end{array}$ & $\begin{array}{l}10 / 103 \\
(9.7)\end{array}$ & $\begin{array}{l}13 / 112 \\
(11.6)\end{array}$ & 0.65 & $0.81(0.34,1.95)$ & 0.63 \\
\hline \multicolumn{6}{|c|}{ - Denominator of the percentage is the total number of patients. } \\
\hline \multicolumn{6}{|c|}{$\mathbf{\wedge}^{\wedge}$ Chi-square /**Fisher Exact test is used to calculate the P-value. } \\
\hline \multicolumn{6}{|c|}{$\begin{array}{l}\text { \$ Propensity score after adjusting for patient's APACHE II score, SOFA score, chronic kidney disease } \\
\text { (CKD), and acute kidney injury (AKI) within } 24 \text { hours of ICU admission to calculate Odds ratio and p- } \\
\text { value. }\end{array}$} \\
\hline \multicolumn{6}{|c|}{$\begin{array}{l}\$ * \text { Denominator of the percentage is non-mechanically ventilated patients with } 24 \text { hours of ICU } \\
\text { admission. }\end{array}$} \\
\hline
\end{tabular}


In patients who received high dosing pharmacological VTE prophylaxis, minor bleeding was higher by 3.5 folds compared with standard dosing of pharmacological VTE prophylaxis (OR $(95 \% \mathrm{Cl}): 3.39$ (1.08$10.61)$, p-value $=0.04)$. The proportion of minor bleeding was $2.3 \%$ in the standard dosing compared with $7.5 \%$ in patients who received high dosing pharmacological VTE prophylaxis. In term of major bleeding and requiring RBCs transfusion during ICU stay, there is no statistical differences between the two groups (OR (95\%Cl): $1.28(0.46-3.53), p$-value $=0.63)$ and $(\mathrm{OR}(95 \% \mathrm{Cl}): 0.80(0.44-1.46), \mathrm{p}$-value $=0.46)$, respectively (Table 1$)$.

\section{Mortality and length of stay}

As shown in Table 2, there was no difference in the 30-day ICU mortality nor in-hospital mortality between the two groups (OR $(95 \% \mathrm{Cl}): 1.26(0.77-2.05)$, $\mathrm{p}$-value $=0.36$ and $\mathrm{OR}(95 \% \mathrm{Cl}): 1.05(0.66-1.68), \mathrm{p}$-value $=$ 0.83 respectively). During ICU stay, the proportion of death was $27.8 \%$ in the standard dosing compared with $31.1 \%$ in high dosing VTE pharmacological prophylaxis (Table 2). 
Table 2

Regression analysis for the outcomes

\begin{tabular}{|c|c|c|c|c|c|}
\hline \multirow[t]{2}{*}{ Outcomes } & \multicolumn{3}{|c|}{ VTE prophylaxis } & \multirow{2}{*}{$\begin{array}{l}\text { Odds Ratio } \\
(95 \% \mathrm{Cl})\end{array}$} & \multirow{2}{*}{$\begin{array}{l}\text { P- } \\
\text { value } \\
\$\end{array}$} \\
\hline & $\begin{array}{l}\text { Standard } \\
\text { dose }\end{array}$ & High dose & $\begin{array}{l}P- \\
\text { value }\end{array}$ & & \\
\hline In-hospital mortality, $\mathrm{n} / \mathrm{N}(\%)^{\Delta}$ & $\begin{array}{l}62 / 169 \\
(36.6)\end{array}$ & $\begin{array}{l}63 / 167 \\
(37.7)\end{array}$ & $0.84^{\wedge \wedge}$ & $1.05(0.66,1.68)$ & 0.83 \\
\hline 30 day- ICU mortality, $\mathrm{n} / \mathrm{N}(\%){ }^{\Delta}$ & $\begin{array}{l}47 / 169 \\
(27.8)\end{array}$ & $\begin{array}{l}54 / 168 \\
(31.1)\end{array}$ & $0.39^{\wedge \wedge}$ & $1.26(0.77,2.05)$ & 0.36 \\
\hline \multirow[t]{2}{*}{$\begin{array}{l}\text { ICU readmission within } 3 \\
\text { months, } \mathrm{n} / \mathrm{N}(\%) ¥\end{array}$} & $\begin{array}{l}10 / 103 \\
(9.7)\end{array}$ & $\begin{array}{l}13 / 112 \\
(11.6)\end{array}$ & 0.65 & $\begin{array}{l}0.81(0.338 \\
, 1.946)\end{array}$ & 0.63 \\
\hline & & & & $\begin{array}{l}\text { Beta- coefficient } \\
(95 \% \mathrm{Cl})\end{array}$ & $\begin{array}{l}\text { P- } \\
\text { value } \\
\$^{*}\end{array}$ \\
\hline MV duration, Median (IQR) \& & $\begin{array}{l}6.0 \\
(1.0,13.0)\end{array}$ & $\begin{array}{l}3.0 \\
(0.0,10.0)\end{array}$ & 0.29 & $\begin{array}{l}-0.17(-0.58 \\
0.24)\end{array}$ & 0.41 \\
\hline $\begin{array}{l}\text { ICU Length of Stay Days, Median } \\
\text { (IQR) \& }\end{array}$ & $\begin{array}{l}9.0 \\
(5.0,15.0)\end{array}$ & $\begin{array}{l}8.0 \\
(5.0,13.0)\end{array}$ & 0.39 & $\begin{array}{l}-0.12(-0.31 \\
0.07)\end{array}$ & 0.23 \\
\hline $\begin{array}{l}\text { Hospital Length of Stay Days, } \\
\text { Median (IQR) \& }\end{array}$ & $\begin{array}{l}17.0 \\
(11.0,24.0)\end{array}$ & $\begin{array}{l}14.0 \\
(10.0,24.0)\end{array}$ & 0.22 & $\begin{array}{l}-0.11(-0.27 \\
0.06)\end{array}$ & 0.20 \\
\hline \multicolumn{6}{|c|}{$\Delta$ The Denominator is the total number of patients } \\
\hline \multicolumn{6}{|c|}{$\&$ ¿ Denominator is the number of patients who have respiratory failure requiring MV during ICU stay } \\
\hline \multicolumn{6}{|c|}{$\&$ Denominator is the number of patients who survived. } \\
\hline \multicolumn{6}{|c|}{ * Unpaired t-test / ^ Wilcoxon rank-sum test is used to calculate the P-value. } \\
\hline \multicolumn{6}{|c|}{${ }^{\wedge}$ Chi-square test is used to calculate the P-value. } \\
\hline \multicolumn{6}{|c|}{ 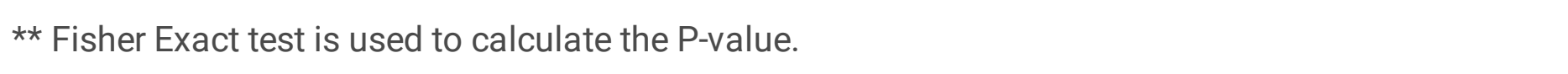 } \\
\hline \multicolumn{6}{|c|}{$\begin{array}{l}\text { S* Propensity score-adjusted negative binomial regression is used to calculate Beta- coefficient } \\
\text { (estimate) and p-value. }\end{array}$} \\
\hline \multicolumn{6}{|c|}{$\begin{array}{l}\text { \$Propensity score after adjusting for patient's APACHE II score, SOFA score, chronic kidney disease } \\
\text { (CKD), and acute kidney injury (AKI) within } 24 \text { hours of ICU admission to calculate Odds ratio and p- } \\
\text { value. }\end{array}$} \\
\hline \multicolumn{6}{|c|}{$¥$ Denominator of the percentage is survival in 30-day ICU mortality. } \\
\hline
\end{tabular}

Among survival, no differences were observed between the two dosing regimens in MV duration (Beta coefficient $=-0.17 ; \mathrm{Cl}=-0.58,0.24 ; \mathrm{p}=0.41)$, ICU LOS (Beta coefficient $=-0.12 ; \mathrm{Cl}=-0.31,0.07 ; \mathrm{p}=0.23$ ) and hospital LOS (Beta coefficient $=-0.11 ; \mathrm{Cl}=-0.27,0.06 ; \mathrm{p}=0.20)$ (Table 2). 


\section{Discussion}

This multicenter retrospective cohort study showed that for patients who received high dosing pharmacological VTE prophylaxis, the differences in venous thromboembolism and any thrombosis case during ICU stay were not significant compared with standard dosing. Furthermore, the odd of minor bleeding was higher by 3.5 folds in those who received high dosing pharmacological VTE prophylaxis compared with standard dosing prophylaxis (OR $(95 \% \mathrm{Cl}): 3.39(1.08-10.61)$, p-value $=0.04)$. There were no statistical differences between the two groups in terms of major bleeding and requiring RBC transfusion during ICU stay. Additionally, there was no difference in the 30- day ICU mortality nor inhospital mortality between the two groups.

Venous thromboembolism (VTE) has emerged as a complication for hospitalized COVID-19 patients. However, the optimal thromboprophylaxis strategy remains uncertain as studies varied in terms of the patient population, type, and dose of anticoagulation and inclusion/ exclusion criteria.

Risk factors for venous thromboembolism are reduced mobility, acute infective illness, admission for critical care, and older age. Thus, critically ill patients admitted to the hospital with COVID-19 should receive pharmacological thromboprophylaxis unless contraindicated. Based on expert opinion, some clinicians who were already prescribing standard dose thromboprophylaxis with LMWH or unfractionated heparin increased the dose to intermediate thromboprophylaxis doses or even therapeutic treatment doses $(10,11,12,13)$. An interim analysis of three randomized trials encompassing about 1000 critically ill patients with COVID-19 was terminated since those who received therapeutic doses of heparin showed increased mortality and major bleeding compared to controls (14). Thus, multiple clinical societies recommend against using treatment doses unless VTE is evident or highly suspected $(15,16)$.

Similar to the results reported by Al-samkari et al., our findings on 352 patients observed no significant difference between standard VTE prophylaxis dosing and the higher intensity prophylaxis dose in thrombosis risk (17). The exact thromboprophylaxis dose is unknown, patient characteristics, in addition to the balance between thrombosis and bleeding risk, are warranted to guide further thromboprophylaxis intensity as endorsed by clinical societies. Patients who received standard doses had higher severity scores (i.e., APACHE II and SOFA scores), procalcitonin levels, fibrinogen levels, and AKI. Albeit all these proposed confounders were further adjusted for baseline differences. Nevertheless, our observation did not result in a significant difference between the two prophylaxis regimens. Additionally, thrombosis risk was evaluated in our patients using the (PADUA) score. Our cohorts were similar, with a median PADUA score of 5 in which both cohorts are classified as high-risk patients for VTE. Similar to other reported data, in our study, we did not observe any significant difference between standard and high dosing of pharmacological prophylaxis with major bleeding events. However, there was a significant difference in minor bleeding events in patients who received high dosing of pharmacological prophylaxis $(2.3 \% \mathrm{vs}$. $7.5 \% ; P=0.04)$. Notably to consider, Al-Samkari et al. did observe a $2.3 \%$ rate in WHO Grade $2-3$ bleeding events (17). The high thrombotic risk associated with COVID-19 mandates us to balance the risk between bleeding and thrombosis. The urge of a randomized clinical trial to address such questions is essential. 
Until then, selection mainly based on patient characteristics and bleeding risk are components to consider when evaluating thromboprophylaxis intensity.

Our results showed no difference in the 30-day ICU mortality nor in-hospital mortality between the groups. A recently published randomized control trial reported a non-significant difference between intermediatedose anticoagulants compared to prophylactic dose in COVID-19 ICU patients' 30-day mortality, thrombosis, and treatment with extracorporeal membrane oxygenation (ECMO) (13), which was consistent with our results after propensity score matching. In contrast, Roomi et al. retrospective cohort study evaluating the impact of therapeutic anticoagulation in COVID-19 patients found lower all-cause mortality in the therapeutic anticoagulation group compared to prophylactic dosing ((OR $3.0595 \% \mathrm{Cl}$ $1.15-8.10 p=0.04)(18)$. Disease severity differences between the groups might explain the differences in mortality among the studies. Our analysis's main limitation is the retrospective observational nature of the study and the possibility of residual confounding despite propensity score matching. Furthermore, the decision to prescribe standard or high dosing pharmacological VTE prophylaxis to COVID-19 patients was guided by the institutional and the Ministry of Health treatment protocols which faced a dynamic change as evidence continued to emerge over time. Moreover, confirmation of clinically evident VTE by routine screening was a culprit to limit exposure in some cases. Lastly, VTE prophylaxis dose adjustment based on patient characteristics might have reflected the results.

\section{Conclusion}

Our multicenter, retrospective cohort study showed that high dosing pharmacological VTE prophylaxis in critically ill COVID-19 patients was not associated with VTE, thrombosis, or mortality benefits but was linked to an increased risk of minor bleeding. Further randomized clinical and interventional studies are required to confirm our findings.

\section{Abbreviations}

Intensive care units (ICUs), Coronavirus disease (COVID-19), Venous thromboembolism (VTE), Mechanical ventilation (MV), Length of Stay (LOS),

\section{Declarations}

\section{Acknowledgments}

Not applicable.

\section{Author contributions}

All authors contributed to data collections, analysis, drafted, revised, and approved the manuscript's final version. 


\section{Funding}

None.

\section{Availability of data and material}

The datasets used and/or analyzed during the current study are available from the corresponding author on reasonable request.

\section{Ethics approval and consent to participate}

The study was approved Biomedical ethical research committee at King Abdulaziz University Hospital with Reference No 554-2. All methods were performed under relevant guidelines and regulations.

Participants' confidentiality was strictly observed throughout the study by using the anonymous unique serial number for each subject and restricting data only to the investigators. Informed consent was waived because of the study's retrospective nature, and the analysis used anonymous clinical data as per the policy of the local research center.

\section{Consent for publication}

Not applicable.

\section{Competing interests}

No author has a conflict of interest in this study.

\section{References}

1. Guan W, Ni Z, Hu Y, Liang W, Ou C, He J, et al. Clinical Characteristics of Coronavirus Disease 2019 in China. N Engl J Med. 2020;382(APRIL):1708-20.

2. Zhou F, Yu T, Du R, Fan G, Liu Y, Liu Z, et al. Clinical course and risk factors for mortality of adult inpatients with COVID-19 in Wuhan, China: a retrospective cohort study. Lancet. 2020;395(March):1054-62.

3. Cevik M, Kuppalli K, Kindrachuk J, Peiris M. Virology, transmission, and pathogenesis of SARS-CoV-2. BMJ. 2020;371(October):1-6.

4. Malas MB, Naazie IN, Elsayed N, Mathlouthi A, Marmor R, Clary B. Thromboembolism risk of COVID19 is high and associated with a higher risk of mortality: A systematic review and meta-analysis. EClinicalMedicine. 2020;100639:29-30.

5. Al Sulaiman KA, Al Juhani OA, Eljaaly K, Alharbi AA, Al Shabasy AM, Alsaeedi AS, et al. Clinical Features and Outcomes of Critically III Patients with Coronavirus Disease 2019 (COVID-19): A Multicenter Cohort Study. Int J Infect Dis [Internet]. 2021;105:180-7. Available from: https://doi.org/10.1016/j.ijid.2021.02.037 
6. Paranjpe I, Fuster V, Lala A, Russak AJ, Glicksberg BS, Levin MA, et al. Association of Treatment Dose Anticoagulation With In-Hospital Survival Among Hospitalized Patients With COVID-19. J Am Coll Cardiol [Internet]. 2020;76(1):122-4. Available from: https://doi.org/10.1016/j.jacc.2020.05.001

7. Antithrombotic Therapy to Ameliorate Complications of COVID-19 (ATTACC) [Internet]. 2021. Available from: https://clinicaltrials.gov/ct2/show/NCT04372589

8. Dosing of Thromboprophylaxis and Mortality in Critically III COVID-19 Patients [Internet]. 2020. Available from: https://clinicaltrials.gov/ct2/show/NCT04593654? term=anticoagulant\&cond=Covid19+critically+ill\&draw $=2 \&$ rank $=6$

9. Anti-thrombotics for Adults Hospitalized With COVID-19 (ACTIV-4) [Internet]. 2021. Available from: https://clinicaltrials.gov/ct2/show/NCT04505774

10. Helms J, Tacquard C, Severac F, Leonard-Lorant I, Ohana M, Delabranche X, et al. High risk of thrombosis in patients with severe SARS-CoV-2 infection: a multicenter prospective cohort study. Intensive Care Med. 2020;46(6):1089-98.

11. F.A. Kloka, M.J.H.A. Kruipb, N.J.M. van der Meerc, M.S. Arbousd, D.A.M.P.J. Gommerse, K.M. Kantf, F.H.J. Kapteina, J. van Paassend, M.A.M. Stalsa, M.V. Huismana HE. Incidence of thrombotic complications in critically ill ICU patients with COVID-19. Thromb Res. 2020;191(January):145-7.

12. Ishan Paranjpe, , Valentin Fuster, Anuradha Lala, Adam J. Russak, Benjamin S. Glicksberg, Matthew A. Levin, Alexander W. Charney, Jagat Narula, Zahi A. Fayad, Emilia Bagiella, Shan Zhao GNN. Association of Treatment Dose Anticoagulation With In-Hospital Survival Among Hospitalized Patients With COVID-19. J Am Coll Cardiol. 2020;76(January):122-4.

13. Investigators I. Effect of Intermediate-Dose vs Standard-Dose Prophylactic Anticoagulation on Thrombotic Events, Extracorporeal Membrane Oxygenation Treatment, or Mortality Among Patients With COVID-19 Admitted to the Intensive Care Unit: The INSPIRATION Randomized Clinical Trial. JAMA [Internet]. 2021 Mar 18; Available from: https://doi.org/10.1001/jama.2021.4152

14. Barnes GD, Burnett A, Allen A, Blumenstein M, Clark NP, Cuker A, et al. Thromboembolism and anticoagulant therapy during the COVID-19 pandemic: interim clinical guidance from the anticoagulation forum. J Thromb Thrombolysis [Internet]. 2020;50(1):72-81. Available from: https://doi.org/10.1007/s11239-020-02138-z

15. Full-dose blood thinners decreased need for life support and improved outcome in hospitalized COVID-19 patients [Internet]. National Heart, Lung, and Blood Institute (NHLBI). Available from: https://www.nih.gov/news-events/news-releases/full-dose-blood-thinners-decreased-need-lifesupport-improved-outcome-hospitalized-covid-19-patients

16. Hematology AS of. ASH Releases Clinical Practice Guidelines on the Use of Preventive Anticoagulation in Patients with COVID-19. 2020.

17. Al-Samkari H, Gupta S, Leaf RK, Wang W, Rosovsky RP, Brenner SK, et al. Thrombosis, Bleeding, and the Observational Effect of Early Therapeutic Anticoagulation on Survival in Critically III Patients With COVID-19. Ann Intern Med [Internet]. 2021 Jan; Available from: https://europepmc.org/articles/PMC7863679 
18. Roomi SS, Saddique M, Ullah W, Haq S, Ashfaq A, Madara J, et al. Anticoagulation in COVID-19: a single-center retrospective study. J community Hosp Intern Med Perspect [Internet]. 2021 Jan 26;11(1):17-22. Available from: https://pubmed.ncbi.nlm.nih.gov/33552407

\section{Supplementary Files}

This is a list of supplementary files associated with this preprint. Click to download.

- Additionalfile1.docx

- Additionalfile2.docx 